\title{
Dietary sugars inhibit biologic functions of the pattern recognition molecule, mannose-binding lectin
}

\author{
Kazue Takahashi ${ }^{1}$, Wei-Chuan Chang $^{1}$, Patience Moyo ${ }^{1}$, Mitchell R. White ${ }^{2}$, Parool Meelu ${ }^{3}$, \\ Anamika Verma ${ }^{2}$, Gregory L. Stahl ${ }^{4}$, Kevan L. Hartshorn ${ }^{2}$, Vijay Yajnik ${ }^{3^{*}}$ \\ ${ }^{1}$ Program of Developmental Immunology, Department of Pediatrics, Massachusetts General Hospital, Harvard Medical School, Bos- \\ ton, USA; \\ ${ }^{2}$ Department of Medicine, Boston University School of Medicine, Boston, USA; \\ ${ }^{3}$ Gastrointestinal Unit, Massachusetts General Hospital, Harvard Medical School, Boston, USA; \\ *Corresponding Author: ktakahashi1@partners.org \\ ${ }^{4}$ Center for Experimental Therapeutics and Reperfusion Injury, Department of Anesthesiology, Perioperative and Pain Medicine, \\ Harvard Institute of Medicine, Harvard Medical School, Boston, USA.
}

Received 17 August 2011; revised 1 September 2011; accepted 9 September 2011.

\begin{abstract}
Mannose-binding lectin (MBL), a mammalian lectin, is a pattern recognition molecule of the innate immune system and recognizes carbohydrates that are exposed on pathogens. In this study, we observed that fructose down regulates MBL-mediated innate immune mechanisms against both influenza A Virus (IAV) and Staphylococcus aureus. These mechanisms include the lectin complement pathway and coagulation enzyme-like activities on both pathogens. Furthermore, fructose also reduces MBL-mediated phagocytosis of $S$. aureus and IAV and MBL-mediated IAV infection to epithelial cells. In contrast, sucrose inhibits MBL-mediated immune mechanisms against $S$. aureus but not IAV. Together, our studies show that dietary sugars, in particular fructose, negatively regulate the innate immunity against viral and bacterial pathogens.
\end{abstract}

Keywords: Mannose-Binding Lectin; Fructose; Influenza A Virus; Staphylococcus Aureus; Complement; Coagulation

\section{INTRODUCTION}

The innate immune system represents the first line of host defense against pathogens. It is widely accepted that in the lumen of our intestines, the innate immune system is constantly interacting with the microbiota $[1,2]$. This interaction is tightly regulated and is essential for both immune tolerance and immunity against pathogens $[3,4]$. How our nutrition affects host-microbiome interactions remains unknown but an increase risk of infection is observed in patients with diabetes and obesity. These diseases have been linked to excess consumption of fructose and fatty foods $[5,6]$. Fructose, in the form of high fructose corn syrup, along with sucrose is the main dietary sugars in our diet [7]. How dietary sugars affect human disease is an important question that remains unanswered. A human study in 1973 showed that dietary sugar intake, but not starch intake, dramatically reduced bacterial phagocytosis [8]. Although the precise mechanisms of this observation have not been understood, these observations support the idea that dietary sugars influence immune functions.

The innate immune system like the adaptive immune system utilizes both cellular and humoral pathways. Cellular defense includes epithelial cells and phagocytes, such as macrophages and neutrophils [9]. Cell surface receptors on innate immune cells together with soluble lectins recognize pathogens by specific pathogen-associated molecular patterns (PAMPs) and therefore termed pattern recognition molecules [10]. MBL, a serum pattern recognition molecule, is primarily synthesized in the liver and in small quantity by the small intestinal epithetlial cells [11-14]. MBL was also identified as an opsonin critical for bacterial (and yeast) phagocytosis $[15,16]$. In addition, it is critical for defense against viruses as MBL is identical to inhibitor found in serum and caused calcium-dependent viral neutralization $[17,18]$. Thus, molecular patterns from virus, bacteria and yeast are recognized by MBL.

Pattern recognition by MBL results in activation of innate immune cascades. For example, MBL activates complement via the lectin pathway, which is mediated by MBL-associated serine protease (MASP) 1-3 [19,20]. MASPs are homologous to serum proteins $\mathrm{C} 1 \mathrm{r}$ and $\mathrm{C} 1 \mathrm{~s}$ 
that activate the classical complement pathway although MASPs evolutionally predate C1r and C1s [21]. MBL/ MASP complex also initiates coagulation via thrombin-like activity [22-24]. Human MBL gene has polymorphisms, producing low and dysfunctional MBL, which have been associated with increased infection susceptibilities as reviewed [25]. Clinical observations in human MBL deficiency were confirmed in an animal model using MBL null mice. These mice have increased infection susceptibility against certain pathogens and reconstitution with exogenous $\mathrm{MBL}$ rescues the phenoltype [26-29].

IAV and $S$. aureus are common human pathogens that are recognized by innate immune molecules, including MBL [30]. IAV is an RNA virus whose surface is enveloped with glycoproteins containing neuraminidase and hemagglutinin, which have glycosylation sites [31]. IAV infection could results in fatal complications, even in individuals who are appeared to be healthy [32,33]. S. aureus is a Gram positive bacteria present on mucosa and skin of healthy individuals [32,34,35]. Although normally innocuous, it may cause serious infections and can develop severe complications leading to much higher morbidity and mortality [36]. This bacterial in- fection has increased problem with rapid emergence of methicillin-resistant S. aureus [37]. In addition, S. aureus can co-infect with influenza virus resulting in increased mortality during influenza epidemics [39].

In this study, we investigated the effects of dietary sugars and its effect on innate immunity against common human pathogens, IAV and $S$. aureus. We observed that fructose negatively regulate MBL-mediated innate immune functions against both IAV and $S$. aureus using well established in vitro experimental design that recapitulates environment present in the intestinal lumen and in blood. These findings represent an important advancement in our understanding the complex interaction between diet and human health.

\section{MATERIALS AND METHODS}

\subsection{Preparation of IAV and S. Aureus}

Both pathogens were prepared as previously described $[28,40]$. Briefly, IAV strain A/Philippine $82\left(\mathrm{H}_{3} \mathrm{~N}_{2}\right)$ was grown in the chorioallantoic fluid of chicken eggs and purified on a discontinuous sucrose gradient. Virus stocks were dialyzed against PBS and aliquots were stored at $-80^{\circ} \mathrm{C}$. HA titers were determined by titration with human type $\mathrm{O}, \mathrm{Rh}^{-}$red blood cells (RBCs) in PBS. Fluorescent foci counts (ffc) were determined by MadinDarby canine kidney (MDCK) cell infection assay as previously described [41]. S. aureus was grown in Columbia media with $2 \% \mathrm{NaCl}$ and used at mid log phase and cfu was determined by culture on tryptic soy agar plates [28].

\subsection{MBL Binding Assay}

This assay was performed using previously described methods with a minor modification [27]. Briefly, 96 assay plates were coated with mannan ( $1 \mu \mathrm{g}$, Sigma, MO), IAV (1000 $\mathrm{HA}^{-1}$ ) or S. aureus (Reynolds CP-5, $5 \times 10^{6} \mathrm{cfu}$ ) in $50 \mu \mathrm{l}$ of a bicarbonate buffer, $\mathrm{pH} 9.5$ and blocked with BSA. The pates were added with indicated concentrations of recombinant human MBL (MBL, a gift from Enzon Pharmaceuticals. A concentration of stock was 1 $\mathrm{mg} / \mathrm{ml}$ ) in $50 \mu \mathrm{l}$ and incubated at room temperature. After rinsing, bound MBL was detected by mouse antihMBL monoclonal Ab (3F8) [42] followed by alkaline-phosphatase conjugated anti-mouse Ab (Promega, WI) and pNTP substrate (Sigma, MO). Reaction was read at OD $415 \mathrm{~nm}$ using SpectraMax M5 (Molecular Devices, CA). For sugar inhibition experiments, indicated concentrations of sugars were mixed together with MBL at $1 \mu \mathrm{g} / \mathrm{ml}$. Binding was expressed as OD415 reading. These assays were performed in triplicates and repeated at least twice. Representative data was shown.

\subsection{Mouse Sera}

MBL knockout (KO) mouse sera were used to provide MASPs [22]. Mouse sera were stored in the $-80^{\circ} \mathrm{C}$ freezer. All animal experiments were performed under a protocol approved by the Subcommittee on Research Animal Care at Massachusetts General Hospital, Boston, MA.

\subsection{Assays of the Lectin Complement Activity and Thrombin-Like Activity}

The lectin pathway assay was performed with a minor modification of previously described method [28]. 96 well plates were prepared as in the binding assay. After wash and blocking, wells were incubated with various concentration of MBL with or without $1 \%$ MBL KO sera and incubated at room temperature. After wash, the wells were incubated with human C4 (Sigma, MO) and incubated at $37^{\circ} \mathrm{C}$. After wash, the wells were incubated with rabbit anti-hC4c $\mathrm{Ab}$ (Dako, CA) followed by alkaline phosphatase-conjugated anti-rabbit $\mathrm{Ab}$ and then with pNTP. The plates were read at $415 \mathrm{~nm}$ and the results were expressed as $\mathrm{U} / \mathrm{ml}$. Pooled human sera with known MBL concentration (State Sera Institute, Denmark) was used to generate a standard curve on mannan-coated wells.

Thrombin-like activity was performed as previously described [22]. Briefly, 384 wells were coated as in the binding assay. After wash, the wells were incubated with 
various concentrations of MBL with or without $1 \% \mathrm{MBL}$ KO sera. After wash, wells were incubated with rhodamine 110-thrombin substrate R22124 (Invitrogen, CA) in $\mathrm{TBS}-\mathrm{CaCl}_{2}$ and read at $500 \mathrm{~nm}$ excitation $/ 520 \mathrm{~nm}$ emission using the SpectraMax M5. The results were expressed as arbitrary units (AU).

For sugar inhibition on mannan, indicated concentrations of various sugars were mixed with MBL $1 \mu \mathrm{g} / \mathrm{ml}$ with or without MBL KO sera. Sugars tested were mannan, N-acetyl-D-glucosamine (GlcNAc), D-fructose, and sucrose (all sugars are from Sigma, MO). For sugar inhibition on IAV and $S$. aureus, sugars at final concentration of $10 \mathrm{mg} / \mathrm{ml}$ was mixed with MBL $1 \mu \mathrm{g} / \mathrm{ml}$. Inhibitory activities were expressed by $\%$ inhibition that was calculated by the formula: [(Activity by MBL) - (Activity by $\mathrm{MBL}+$ sugars $)] \times 100 \div$ (Activity by $\mathrm{MBL}$ ). In the formula, MBL was replaced with "MBL + MBL KO sera" for the lectin complement pathway and thrombin-like activity.

These assays were performed in triplicates and repeated at least twice and representative data was shown.

\subsection{Uptake and Binding of IAV and S. Aureus by Phagocytes}

Assays were performed as previously described $[28,43,44]$. Briefly, resident peritoneal macrophages of C57B/6J (Jackson Laboratories, MI) mice were obtained by peritoneal lavage and re-suspended in HBSS. In the total $50 \mu \mathrm{l}$ reaction volume, $1 \times 10^{5}$ peritoneal macrophages were mixed with FITC-labeled $S$. aureus (FITCS. aureus) with $\mathrm{MBL}$ at $10 \mu \mathrm{g} / \mathrm{ml}$ and with or without fructose or galactose at $10 \mathrm{mg} / \mathrm{ml}$. The mixture was incubated on ice for $10 \mathrm{~min}$ and then further incu- bated for $20 \mathrm{~min}$ at $37^{\circ} \mathrm{C}$.

Neutrophils from healthy volunteer donors were isolated to greater than $95 \%$ purity by using dextran precipitation, followed by a Ficoll-Hypaque gradient separation for removal of non-nuclear cells and hypotonic lysis to eliminate contaminating erythrocytes [40]. In the total $100 \mu \mathrm{l}$ reaction volume, $5 \times 10^{5}$ neutrophils were pretreated at $37^{\circ} \mathrm{C}$ for $30 \mathrm{~min}$ and then were further incubated for $1 \mathrm{~h}$ at $37^{\circ} \mathrm{C}$ with FITC-IAV with MBL at 10 $\mu \mathrm{g} / \mathrm{ml}$ and with or without fructose or galactose at 10 $\mathrm{mg} / \mathrm{ml}$ [44].

Flow cytometry assays were performed on a FACSCalibur ${ }^{\mathrm{TM}}$ (BD Biosciences) with and without addition of $0.04 \%$ trypan blue, which quenches extracellular fluorescence, representing binding [28,44]. Results were analyzed using CELLQuest ${ }^{\mathrm{TM}}$ software. Results were expressed as \% of MBL-mediated binding and uptake of FITC-S. aureus (mean fluorescent $\times \%$ total) of triplicate samples.

\subsection{IAV Neutralizing Activity Assay (Focus Assay)}

This assay was performed using MDCK cells as in 2.1. IAV was preincubated with MBL at $1 \mu \mathrm{g} / \mathrm{ml}$ with or without fructose at $10 \mathrm{mg} / \mathrm{ml}$. These mixtures were incubated with MDCK cells to determine IAV infection (ffc). The assay was repeated 5 times and all data were combined.

\subsection{Statistical Analysis}

All data were analyzed by Student t-tests to "compare mean of each pair" using JMP software (SAS institute Inc., NC). $\mathrm{P}$ values less than 0.05 was considered to be significant.

\section{RESULTS}

\subsection{Fructose and Sucrose Inhibit Biologic Functions of MBL: Studies on Mannan}

Mannan is an established MBL ligand derived from yeast and in the presence of MASPs, it can activate both complement and thrombin pathways [22]. In this study, we used MBL KO sera as a source for MASPs and recombinant human MBL (Enzon Biochemicals). As shown in Figures 1(A)-(B), MBL bound to mannan and activated the lectin complement pathway and thrombin-like activity, in a dose dependent manner.

We investigated effects of dietary sugars on MBLmannan interaction and subsequent MBL-mediated biologic functions. Fructose inhibited MBL-mannan interaction as determined by ELISA (Figure 2(A)). Fructose at $10 \mathrm{mg} / \mathrm{ml}$ inhibited the MBL-mannan binding by $82 \%$, which was greater than observed by GlcNAc, 54\% (data not shown). Furthermore, fructose inhibited the lectin complement pathway and thrombin-like activities in a dose dependent manner. Its inhibitory effect on biologic function was detectable even at lower concentrations of $0.4 \mathrm{mg} / \mathrm{ml}$ and $2 \mathrm{mg} / \mathrm{ml}$ (Figure 2) and comparable to that of mannan at a concentration of $10 \mathrm{mg} / \mathrm{ml}$ for both the lectin complement and thrombin-like activities (Figures 2(B)-(C)).

Sucrose also inhibited these activities in a dose dependent manner although it did not inhibit MBL-mannan binding (Figure 2). Compared to fructose, the inhibitory effect on the lectin complement pathway activity was significantly lower, which was only $53 \%$ inhibition at a concentration of $10 \mathrm{mg} / \mathrm{ml}$ (Figure 2(B)). In contrast, sucrose inhibition of thrombin-like activity was over all comparable to that of fructose and reached a plateau, $66 \%$ and $65 \%$ inhibition at $2 \mathrm{mg} / \mathrm{ml}$ and $10 \mathrm{mg} / \mathrm{ml}$, respectively (Figure 2(C)). 
Baseline functions(mannan study)

A)

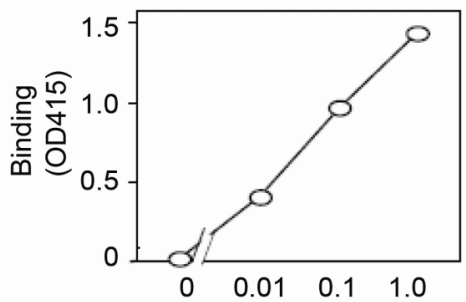

B)

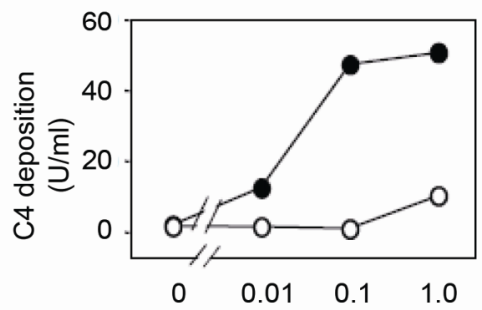

C)

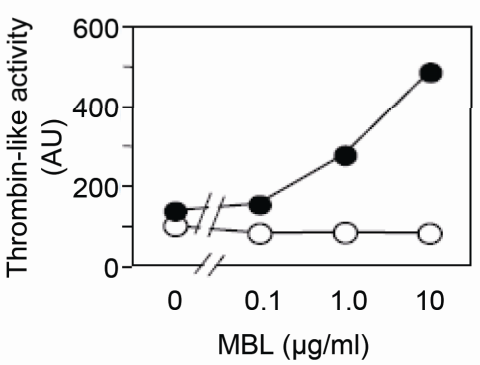

$\multimap-M B L$

MBL + MASP

Figure 1. Recombinant human MBL (MBL)mediated functions and sugar inhibition against mannan. (A) Binding. (B) C4 deposition. (C) Thrombin-like activity.

Based on these experiments, fructose IC50 for binding, the lectin complement pathway and thrombin-like activities were $22 \mathrm{mM}, 5.5 \mathrm{mM}$ and $5.5 \mathrm{mM}$, respectively, while sucrose IC50 were $>11 \mathrm{mM}, 2.8 \mathrm{mM}$ and $2.6 \mathrm{mM}$. In contrast to these dietary sugars, dextran, which is a polyglucose and is similar to starch, did not inhibit binding and the lectin complement pathway activation of MBL on mannan even at $10 \mathrm{mg} / \mathrm{ml}$ (data not shown).

\subsection{Fructose Inhibits Biologic Functions of MBL: Studies on IAV}

MBL bound to IAV in a dose dependent manner, confirming that MBL recognizes IAV (Figure 3(A)) $[45,46]$. MBL-IAV binding was inhibited by $8 \%$ and $14 \%$ by mannan and fructose, respectively, while sucrose did not show inhibitory effect (Figure 3(B)). To compare the effects of fructose, mannan was used as a positive control in IAV studies. Despite the low level inhibition of MBL-IAV binding, mannan significantly inhibited the

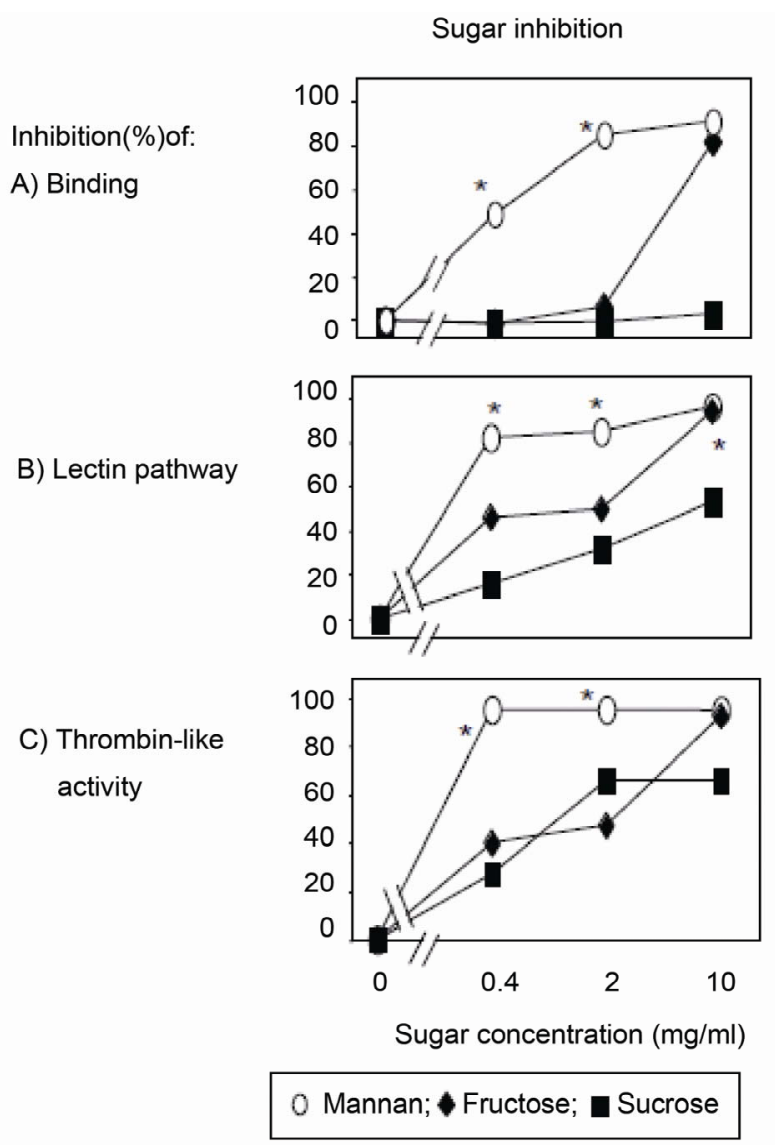

Figure 2. (A)-(C) Sugar inhibition assays of binding, the lectin complement pathway, and thrombin-like activity, respectively. Data were expressed as mean $\pm \mathrm{SEM}$, which were smaller than sizes of symbols. ${ }^{*} p<0.0005$.

lectin complement activation and thrombin-like activities, by $87 \%$ and $84 \%$ inhibition, respectively (Figures 3(C)-(D)). Accordingly, fructose $(10 \mathrm{mg} / \mathrm{ml})$ also significantly inhibited the lectin complement and thrombin-like activities, by $88 \%$ and $75 \%$, respectively (Figures 3(C)-(D)). Sucrose also showed weak inhibition on thrombin-like activity but not on the lectin complement activation (Figure 3(D)). Thus, fructose but not sucrose inhibited MBL-mediated biologic functions, the lectin complement and thrombin-like activities, by 5-fold compared with binding inhibition.

MBL, an opsonin up regulates phagocytosis of pathogens. We reasoned that since fructose influences humoral arm of innate immunity, it may also disrupt cellular arm as well. To study IAV uptake we designed two experiments. First, we observed that MBL-mediated uptake of FITC-IAV by human neutrophils was significantly inhibited by $37 \%$ in the presence of fructose at 10 $\mathrm{mg} / \mathrm{ml}$ (Figure 3(E)). However, the MBL-mediated viral uptake was not inhibited by galactose, which is not an MBL ligand (Figure 3(E)) [47,50]. Second, fructose also 


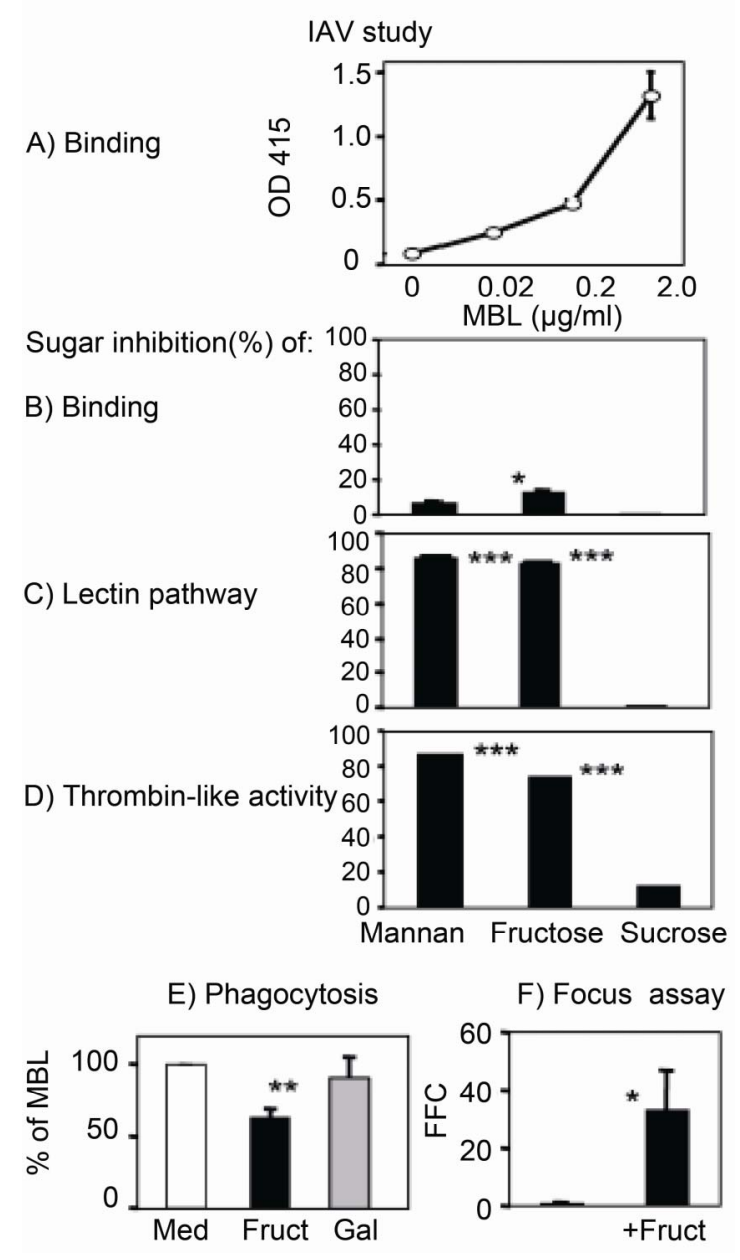

Figure 3. MBL-mediated functions and sugar inhibition against IAV. (A) MBL-binding to IAV. Sugar inhibition of binding (B), C4 deposition (C), and thrombin-like activity (D). (E) Phagocytosis assays of FITC-IAV by human neutrophils. Fruct and Gal indicated fructose and galactose, respectively. (F) IAV neutralizing assay. Data were expressed as mean $\pm \mathrm{SEM}$, and represent $p<0.05, p<0.001$ and $p<0.0005$, respectively.

inhibited MBL's IAV neutralization activity, which is determined by infectivity of IAV to epithelial cells (MDCK) as IAV infection increased when fructose was added (Figure 3(F)). Taken together, these results demonstrated that fructose down-regulated MBL-mediated viral phagocytosis and viral neutralization.

\subsection{Fructose and Sucrose Inhibit Biologic Functions of MBL: Studies on S. Au- reus}

Similar to against IAV, MBL bound to $S$. aureus, in a dose dependent manner (Figure 4(A)). MBL-binding was minimally inhibited only $5 \%-6 \%$ by either mannan (positive control ligand) or dietary sugars, fructose or sucrose (Figure 4(B)). Despite the negligible-level binding
S. aureus study

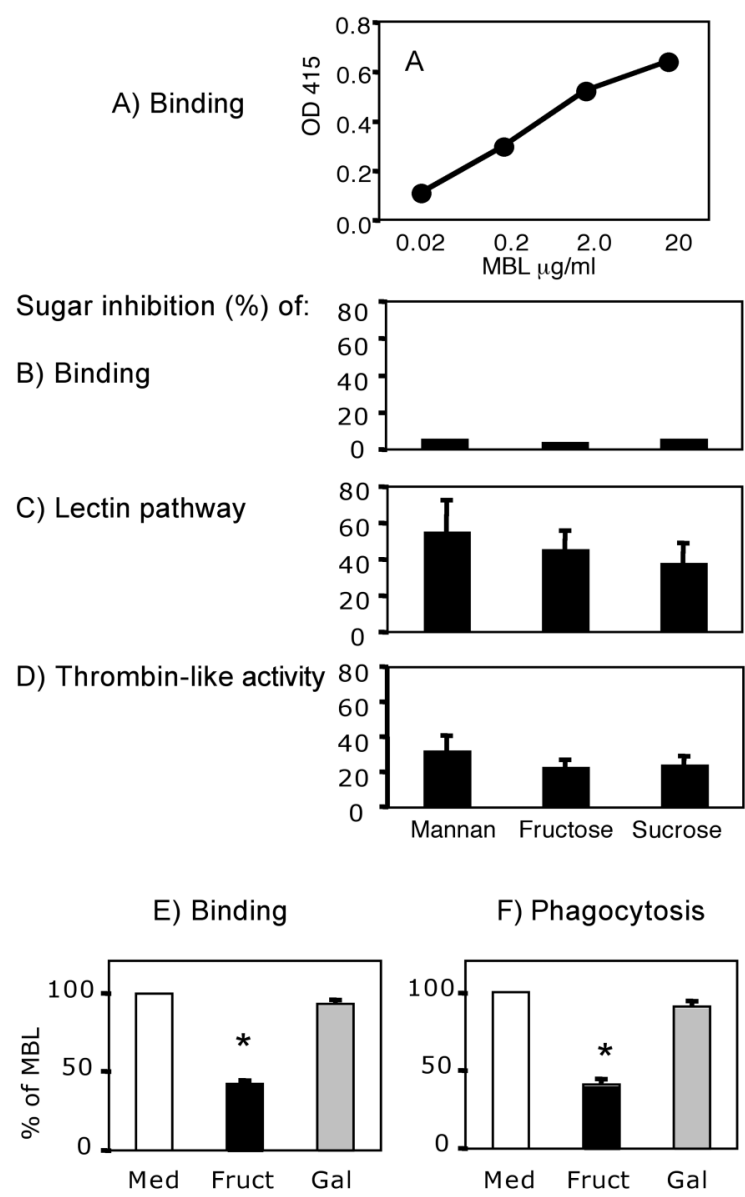

Figure 4. MBL-mediated functions and sugar inhibition against $S$. aureus. (A) MBL-binding to $S$. aureus. Sugar inhibition assays of binding, (B) C4 deposition, (C) and thrombin-like activity, (D) Binding, (E) and phagocytosis, (F) assay of FITC-S. aureus by macrophages. Fruct and Gal indicated fructose and galactose, respectively. Data were expressed as mean \pm SEM, some of which were smaller than symbols. *represents $p<0.0005$.

inhibition, all sugars, even sucrose (all at $10 \mathrm{mg} / \mathrm{ml}$ ) significantly inhibited the lectin complement activation and thrombin-likeactivities, in between the range of $39 \%$ $66 \%$ and $24 \%-36 \%$, respectively (Figures 4(C)-(D)). Once again, compared with binding inhibition, these sugars' inhibitory effects were $5-10$ fold greater on the lectin complement activation and thrombin-like activeties.

Regarding FITC-S. aureus binding to Regarding FIT C-S. aureus binding to macrophages, it was signifycantly inhibited by $60 \%$ in the presence of fructose (Figure 4(E)). Similarly, MBL-mediated phagocytosis of FITC-S. aureus was significantly inhibited by $60 \%$ in the presence of fructose (Figure 4(F)). However, these activeties were not inhibited by galactose, which is not 
an MBL ligand (Figures 4(E)-(F)) [47,50]. Taken together, these data demonstrated that fructose negatively regulated MBL-mediated anti-bacterial cellular functions.

\section{DISCUSSION}

Binding of pattern recognition molecules to pathogens is a crucial step to initiate a variety of subsequent signaling cascades in innate immunity, the first line of host defense mechanisms. These mechanisms include the lectin complement pathway activation and thrombin-like activities $[48,49]$. The results of the current study demonstrate that MBL initiates these activities on common human pathogens. A highly significant and clinically relevant finding from this study is striking inhibitory effects by fructose and some extent by sucrose on these innate immune functions, as we summarize our findings in Figure 5(a).

Using functional in vitro assays, we demonstrate that both fructose and sucrose are MBL recognition molecules, and are similar to other MBL recognition molecules, namely, D-mannose and GlcNAc [47,50,51]. Our findings support recent report that fructose-lysine bound to MBL and formed complexes with MASP [52]. These two dietary sugars show differential kinetics in inhibition of MBL-ligand binding, suggesting that there may be specific molecular residues that govern these interactions. The importance of dietary sugar interaction with MBL is underscored by our studies on two common pathogens. Using both viral and bacterial pathogen binding to MBL, we demonstrate that dietary sugars, specifically fructose has a dramatic negative consequence. Mannan, fructose and sucrose had similar low level, inhibition of MBL binding to immobilized pathogens. However, the biologic pathways, activation of the lectin complement pathway and coagulation, downstream of MBL are significantly down regulated, particularly in presence of sucrose and fructose. Using an established bacterial and viral phagocytosis assay we show that fructose neutralizes pathogen entry into phagocytes, such as macrophages and neutrophils, the primary cell defense in innate immunity.

Differential effects of two dietary sugars were also observed on MBL biologic function. We note that sucrose has minimal influence on MBL-IAV (viral) interactions (Figure 5(a)). This is in contrast to MBL-S. aureus (bacterial) and MBL-mannan (fungal) interactions (Figure 5(a)). It is possible that diet high in sucrose may not affect viral innate immunity but could influence both anti-fungal and anti-bacterial host defense. MBL functions as an opsonin, which is a key function of MBL-mediated anti-bacterial defense mechanism [28,53, 54]. As expected, fructose reduced MBL-mediated phagocytosis of IAV and S. aureus, suggesting that fructose reduces not only MBL-mediated humoral functions (activation of complement and coagulation) but also MBL-mediated cellular response. Our previous study has demonstrated that the latter is required to reduce bacterial growth against $S$. aureus [28]. On the contrary, dextran, which is poly-glucose and is a similar to starch, did not inhibit MBL-associated functions, such as binding and the lectin complement activation. Our finding may partly explain the study in 1973, showing that bacterial phagocytosis by phagocytes isolated from healthy volunteers was dramatically reduced by intake of dietary sugars, including fructose, but was unaffected by starch intake [8].

Our results also suggest that dietary sugars, in particular fructose has negative effect on innate immunity in a dose dependent manner. Therefore, it is conceivable that dietary sugars at low concentrations may not have any pathological consequence. It has been observed that in fructose fed rat, fructose concentration in the hepatic portal vein reaches to $0.4 \mathrm{mg} / \mathrm{ml}$, which significantly inhibited MBL-mediated biologic functions in our study [55]. Consumption of these dietary sugars, more so for fructose, has skyrocketed in recent years and has been linked to a recent increase in metabolic disease, including diabetes and obesity [5-7]. It is also know that diabetic patients have increased susceptibility to infection [6], which has been attributed to a poor circulation in these patients. Our findings would suggest that those dietary sugars might also be responsible by directly reducing innate immune functions as blood fructose levels reportedly increase after fructose consumption in diabetes [56]. Therefore, one can speculate that intake of high levels of dietary sugar may induce a similar situation to MBL deficiency, which has been associated with infection susceptibility [25].

Coagulation, which is mediated by thrombin, is not generally thought to be microbicidal, nevertheless it is a primitive innate immune host defense mechanism, particularly in invertebrates that do not have phagocytes. For example, tachylectins in horseshoe crab clots lipopolysaccharide and -glucan (PAMPs of Gram negative bacteria and fungi, respectively), providing innate immune protection [57]. Clotting may also contain pathogen invasion locally, thereby preventing systemic dissemination of pathogen. Our recent study demonstrates that MBL $\mathrm{KO}$ mice, which are susceptible to IAV and S. aureus infection, have reduced clotting ability [22]. One can speculate that elevated fructose in diabetic patients may reduce local coagulation, in allowing easy pathogen escape into the host. We propose that dietary sugars, in particular high dose of fructose weakens the innate immune protection, which is initiated by pattern recognition molecules, including MBL (Figure 5(b)). It is also conceivable that pattern recognition molecules may play 
(a)

\begin{tabular}{|l|c|c|c|c|}
\hline \multirow{3}{*}{$\begin{array}{l}\text { Dietary } \\
\text { sugars }\end{array}$} & \multirow{2}{*}{$\begin{array}{l}\text { MBL-mediated } \\
\text { functions }\end{array}$} & \multicolumn{3}{|c|}{ Inhibitory effects of sugars } \\
\cline { 3 - 5 } & & $\begin{array}{l}\text { IAV } \\
\text { (viral) }\end{array}$ & $\begin{array}{l}\text { S. aureus } \\
\text { (bacterial) }\end{array}$ & $\begin{array}{c}\text { Mannan } \\
\text { (fungal) }\end{array}$ \\
\hline \multirow{4}{*}{ Fructose } & Binding & + & $+/-$ & +++ \\
\cline { 2 - 5 } & LC & +++ & ++ & +++ \\
\cline { 2 - 5 } & Coag & +++ & + & +++ \\
\cline { 2 - 5 } & Phagcoytosis & + & + & ND \\
\hline \multirow{3}{*}{ Sucrose } & Binding & - & $+/-$ & - \\
\cline { 2 - 5 } & LC & - & ++ & ++ \\
\cline { 2 - 5 } & Coag & + & + & ++ \\
\hline
\end{tabular}

Note: LC. The lectin complement pathway; coag, thrombin-like activity.

There was no inhibition of MBL binding and LC on mannan by dextran

glycan and of phagocytosis of S. aureus and IAV by galactose.

(b)
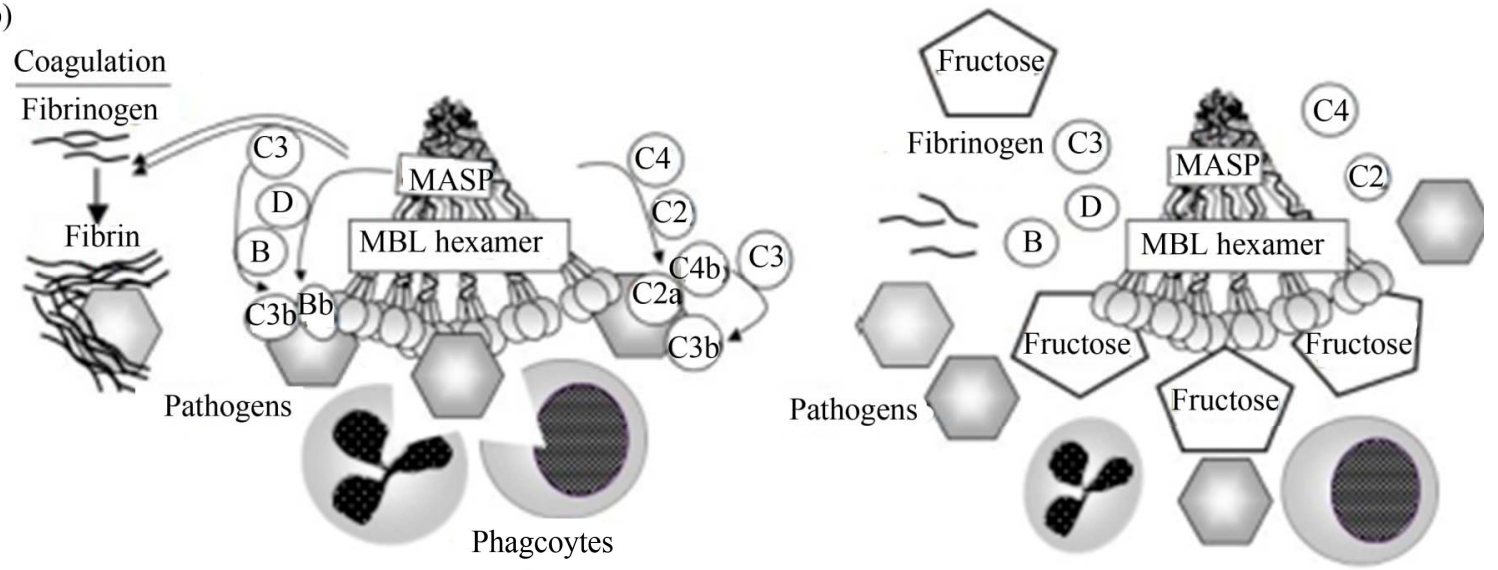

Figure 5. (a) The summary of the findings from this investigation are presented in a table form showing the differential effects of sugar on MBL-pathogen interaction. Note: LC, the lectin complement pathway; Coag, coagulation. Level of inhibition is presented as follows: -no effect; +/-marginal; + low; ++ intermediate; and +++ high. ND indicates not done. (b) The potential mechanism for the observed inhibition of innate immune mechanisms by fructose, which down regulates MBL-mediated anti-microbicidal activities, including activation of complement, coagulation and phagocytosis. Fructose can be replaced with sucrose, depending on its concentration and pathogen.

roles in maintaining healthy commensal microbiota by fending off pathogenic bacteria [58,59]. In turn, the healthy microbiota would stimulate and strengthen the innate immune defense mechanisms. Diet can also affect defense mechanisms. Diet can also affect microbiota composition in mice underscoring the tight link between diet and metabolism of intestinal bacteria [60]. Thus, elucidating the relationships between diet, microbiota and innate immune system will be central to our understanding of human health

\section{ACKNOWLEDGEMENTS}

We would like to thank Enzon pharmaceuticals for providing MBL. The study was in part, supported by UO1 AI074503, R21 AI077081 and 1U24AI092660. No. author has conflict of interest.

\section{REFERENCES}

[1] Edelman, S.M. and Kasper, D.L. (2008) Symbiotic commensal bacteria direct maturation of the host immune system. Current Opinion in Gastroenterology, 24, 720724. doi:10.1097/MOG.0b013e32830c4355

[2] Viswanathan, V.K. and Hecht, G. (2000) Innate immunity and the gut. Current Opinion in Gastroenterology, 16, 546-551. doi:10.1097/00001574-200011000-00015

[3] Chaplin, D.D. (2010) Overview of the immune response. Journal of Allergy and Clinical Immunology, 125, S3S23. doi:10.1016/j.jaci.2009.12.980

[4] LaRosa, D.F., Rahman, A.H. and Turka, L.A. (2007) The innate immune system in allograft rejection and tolerance. The Journal of Immunology, 178, 7503-7509.

[5] Halford, J.C. (2004) Clinical pharmacotherapy for obesity: current drugs and those in advanced development Current Drug Targets, 5, 637-646. 
doi:10.2174/1389450043345191

[6] McGuinness, O.P. and Cherrington, A.D. (2003) Effects of fructose on hepatic glucose metabolism. Current Opinion in Clinical Nutrition \& Metabolic Care, 6, 441-448. doi:10.1097/01.mco.0000078990.96795.cd

[7] Tappy, L. and Le, K.A. (2010) Metabolic effects of fructose and the worldwide increase in obesity. Physiological Reviews, 90, 23-46. doi:10.1152/physrev.00019.2009

[8] Sanchez, A., Reeser, J.L., Lau, H.S., Yahiku, P.Y., Willard, R.E., McMillan, P.J., Cho, S.Y., Magie, A.R. and Register, U.D. (1973) Role of sugars in human neutrophilic phagocytosis. The American Journal of Clinical Nutrition, 26, 1180-1184.

[9] Silva, M.T. (2010) When two is better than one: Macrophages and neutrophils work in concert in innate immunity as complementary and cooperative partners of a myeloid phagocyte system. Journal of Leukocyte Biology, 87, 93-106. doi:10.1189/jlb.0809549

[10] Hoffmann, J.A., Kafatos, F.C., Janeway, C.A. and Ezekowitz, R.A. (1999) Phylogenetic perspectives in innate immunity. Science, 284, 1313-1318. doi:10.1126/science.284.5418.1313

[11] Uemura, K., Saka, M., Nakagawa, T., Kawasaki, N., Thiel, S., Jensenius, J.C. and Kawasaki, T. (2002) L-MBP is expressed in epithelial cells of mouse small intestine. The Journal of Immunology, 169, 6945-6950.

[12] Hansen, S., Thiel, S., Willis, A., Holmskov, U. and Jensenius, J.C. (2000) Purification and characterization of two mannan-binding lectins from mouse serum. The Journal of Immunology, 164, 2610-2618.

[13] Oka, S., Ikeda, K., Kawasaki, T. and Yamashina, I. (1988) Isolation and characterization of two distinct mannan-binding proteins from rat serum. Archives of Biochemistry and Biophysics, 260, 257-266.

[14] Agah, A., Montalto, M.C., Young, K. and Stahl, G.L. (2001) Isolation, cloning and functional characterization of porcine mannose-binding lectin. Immunology, 102, 338-343. doi:10.1046/j.1365-2567.2001.01191.x

[15] Sumiya, M., Super, M., Tabona, P., Levinsky, R.J., Arai, T., Turner, M.W. and Summerfield, J.A. (1991) Molecular basis of opsonic defect in immunodeficient children. Lancet, 337, 1569-1570.

[16] Super, M., Thiel, S., Lu, J., Levinsky, R.J. and Turner, M.W. (1989) Association of low levels of mannan-binding protein with a common defect of opsonisation. Lancet, 2, 1236-1239.

[17] Burnet, F.M. and McCrea, J.F. (1946) Inhibitory and inactivating action of normal ferret sera against an influenza virus strain. Australian Journal of Experimental Biology \& Medical Science, 24, 277-282. doi:10.1038/icb.1946.41

[18] Anders, E.M., Hartley, C.A. and Jackson, D.C. (1990) Bovine and mouse serum beta inhibitors of influenza A viruses are mannose-binding lectins. Proceedings of the National Academy of Sciences of the United States of America, 87, 4485-4489. doi:10.1073/pnas.87.12.4485

[19] Thiel, S., Vorup-Jensen, T., Stover, C.M., Schwaeble, W., Laursen, S.B., Poulsen, K., Willis, A.C., Eggleton, P., Hansen, S., Holmskov, U., Reid, K.B. and Jensenius, J.C. (1997) A second serine protease associated with mannan-binding lectin that activates complement. Nature, 386, 506-510. doi:10.1038/386506a0

[20] Matsushita, M. and Fujita, T. (1992) Activation of the classical complement pathway by mannose-binding protein in association with a novel C1s-like serine protease. The Journal of Experimental Medicine, 176, 1497-1502. doi:10.1084/jem.176.6.1497

[21] Fujita, T., Endo, Y. and Nonaka, M. (2004) Primitive complement system-recognition and activation. Molecular Immunology, 41, 103-111. doi:10.1016/j.molimm.2004.03.026

[22] Takahashi, K., Chang, W.C., Takahashi, M., Pavlov, V., Ishida, Y., La Bonte, L., Shi, L., Fujita, T., Stahl, G.L. and Van Cott, E.M. (2011) Mannose-binding lectin and its associated proteases (MASPs) mediate coagulation and its deficiency is a risk factor in developing complications from infection, including disseminated intravascular coagulation. Immunobiology, 216, 96-102. doi:10.1016/j.imbio.2010.02.005

[23] Krarup, A., Wallis, R., Presanis, J.S., Gal, P. and Sim, R.B. (2007) Simultaneous activation of complement and coagulation by MBL-associated serine protease 2. PLoS ONE, 2, e623. doi:10.1371/journal.pone.0000623

[24] Presanis, J.S., Hajela, K., Ambrus, G., Gal, P. and Sim, R.B. (2004) Differential substrate and inhibitor profiles for human MASP-1 and MASP-2. Molecular Immunology, 40, 921-929. doi:10.1016/j.molimm.2003.10.013

[25] Takahashi, K. and Ezekowitz, R.A. (2005) The role of the mannose-binding lectin in innate immunity. Clinical Infectious Diseases, 7, S440- S444.

[26] Steffensen, R., Thiel, S., Varming, K., Jersild, C. and Jensenius, J.C. (2000) Detection of structural gene mutations and promoter polymorphisms in the mannan-binding lectin (MBL) gene by polymerase chain reaction with sequencespecific primers. Journal of Immunological Methods, 241, 33-42. doi:10.1016/S0022-1759(00)00198-8

[27] Moller-Kristensen, M., Ip, W.K., Shi, L., Gowda, L.D., Hamblin, M.R., Thiel, S., Jensenius, J.C., Ezekowitz, R.A. and Takahashi, K. (2006) Deficiency of mannose-binding lectin greatly increases susceptibility to postburn infection with pseudomonas aeruginosa. The Journal of Immunology, 176, 1769-1775.

[28] Shi, L., Takahashi, K., Dundee, J., Shahroor-Karni, S., Thiel, S., Jensenius, J.C., Gad, F., Hamblin, M.R., Sastry, K.N. and Ezekowitz, R.A. (2004) Mannose-binding lectin-deficient mice are susceptible to infection with Staphylococcus aureus. The Journal of Experimental Medicine, 199, 1379-1390. doi:10.1084/jem.20032207

[29] Gadjeva, M., Paludan, S.R., Thiel, S., Slavov, V., Ruseva, M., Eriksson, K., Lowhagen, G.B., Shi, L., Takahashi, K., Ezekowitz, A. and Jensenius, J.C. (2004) Mannan-binding lectin modulates the response to HSV-2 infection. Clinical \& Experimental Immunology, 138, 304-311. doi:10.1111/j.1365-2249.2004.02616.x

[30] Fraser, I.P., Koziel, H. and Ezekowitz, R.A. (1998) The serum mannose-binding protein and the macrophage mannose receptor are pattern recognition molecules that link innate and adaptive immunity. Seminars in Immunology, 10, 363-372. doi:10.1006/smim.1998.0141

[31] Nayak, D.P., Hui, E.K. and Barman, S. (2004) Assembly and budding of influenza virus. Virus Research, 106, 147-165. doi:10.1016/j.virusres.2004.08.012

[32] Lynch, J.P. and Walsh, E.E. (2007) Influenza: Evolving strategies in treatment and prevention. Seminars in Respiratory and Critical Care Medicine, 28, 144-158. 
doi:10.1055/s-2007-976487

[33] Munoz, F.M. (2003) Influenza virus infection in infancy and early childhood. Paediatric Respiratory Reviews, 4, 99-104. doi:10.1016/S1526-0542(03)00027-7

[34] Cate, T.R. (1998) Impact of influenza and other community-acquired viruses. Seminars in Respiratory Infections, 13, 17-23.

[35] Martin, M.A. (1993) Nosocomial infections in intensive care units: An overview of their epidemiology, outcome and prevention. New Horizons, 1, 162-171.

[36] Cosgrove, S.E., Qi, Y., Kaye, K.S., Harbarth, S., Karchmer, A.W. and Carmeli, Y. (2005) The impact of methicillin resistance in Staphylococcus aureus bacteremia on patient outcomes: Mortality, length of stay, and hospital charges. [see comment]. Infection Control and Hospital Epidemiology, 26, 166-174. doi:10.1086/502522

[37] Johnston, B.L. (1994) Methicillin-resistant Staphylococcus aureus as a cause of community-acquired pneumonia-a critical review. Seminars in Respiratory Infections, 9, 199-206.

[38] Sethi, S. (2002) Bacterial pneumonia. Managing a deadly complication of influenza in older adults with comorbid disease. Geriatrics, 57, 56-61.

[39] Morens, D.M., Taubenberger, J.K. and Fauci, A.S. (2008) Predominant role of bacterial pneumonia as a cause of death in pandemic influenza: Implications for pandemic influenza preparedness. [see comment]. Journal of Infectious Diseases, 198, 962-970. doi:10.1086/591708

[40] Hartshorn, K.L., Collamer, M., Auerbach, M., Myers, J.B., Pavlotsky, N. and Tauber, A.I. (1988) Effects of influenza A virus on human neutrophil calcium metabolism. The Journal of Immunology, 141, 1295-1301.

[41] Hartshorn, K.L., Sastry, K.N., Chang, D., White, M.R. and Crouch, E.C. (2000) Enhanced anti-influenza activity of a surfactant protein D and serum conglutinin fusion protein. American Journal of Physiology-Lung Cellular and Molecular Physiology, 278, L90-98.

[42] Collard, C.D., Montalto, M.C., Reenstra, W.R., Buras, J.A. and Stahl, G.L. (2001) Endothelial oxidative stress activates the lectin complement pathway: role of cytokeratin 1. American Journal of Pathology, 159, 1045-1054. doi:10.1016/S0002-9440(10)61779-8

[43] Hartshorn, K.L., White, M.R., Shepherd, V., Reid, K., Jensenius, J.C. and Crouch, E.C. (1997) Mechanisms of anti-influenza activity of surfactant proteins $\mathrm{A}$ and D: comparison with serum collectins. American Journal of Physiology, 273, L1156-L1166.

[44] Lee, R.M., White, M.R. and Hartshorn, K.L. (2006) Influenza a viruses upregulate neutrophil toll-like receptor 2 expression and function. Scandinavian Journal of Immunology, 63, 81-89. doi:10.1111/j.1365-3083.2005.01714.x

[45] White, M.R., Crouch, E., Chang, D., Sastry, K., Guo, N., Engelich, G., Takahashi, K., Ezekowitz, R.A. and Hartshorn, K.L. (2000) Enhanced antiviral and opsonic activity of a human mannose-binding lectin and surfactant protein D chimera. The Journal of Immunology, 165, 2108-2115.

[46] Kase, T., Suzuki, Y., Kawai, T., Sakamoto, T., Ohtani, K., Eda, S., Maeda, A., Okuno, Y., Kurimura, T. and Wakamiya, N. (1999) Human mannan-binding lectin inhibits the infection of influenza A virus without complement. Immunology, 97, 385-392. doi:10.1046/j.1365-2567.1999.00781.x

[47] Weis, W.I., Drickamer, K. and Hendrickson, W.A. (1992) Structure of a C-type mannose-binding protein com- plexed with an oligosaccharide. Nature, 360, 127-134. doi: $10.1038 / 360127 \mathrm{a} 0$

[48] Zipfel, P.F. (2009) Complement and immune defense: from innate immunity to human diseases. Immunology Letters, 126, 1-7. doi:10.1016/j.imlet.2009.07.005

[49] Muta, T. and Iwanaga, S. (1996) The role of hemolymph coagulation in innate immunity. Current Opinion in Immunology, 8, 41-47. doi:10.1016/S0952-7915(96)80103-8

[50] Montalto, M.C., Collard, C.D., Buras, J.A., Reenstra, W.R., McClaine, R., Gies, D.R., Rother, R.P. and Stahl, G.L. (2001) A keratin peptide inhibits mannose-binding lectin. The Journal of Immunology, 166, 4148-4153.

[51] Holt, P., Holmskov, U., Thiel, S., Teisner, B., Hojrup, P. and Jensenius, J.C. (1994) Purification and characterization of mannan-binding protein from mouse serum. scand. The Journal of Immunology, 39, 202-208. doi:10.1111/j.1365-3083.1994.tb03361.x

[52] Fortpied, J., Vertommen, D. and Van Schaftingen, E. (2010) Binding of mannose-binding lectin to fructosamines: A potential link between hyperglycaemia and complement activation in diabetes. Diabetes/Metabolism Research and Reviews, 26, 254-260. doi:10.1002/dmrr. 1079

[53] Park, K.H., Kurokawa, K., Zheng, L., Jung, D.J., Tateishi, K., Jin, J.O., Ha, N.C., Kang, H.J., Matsushita, M., Kwak, J.Y., Takahashi, K. and Lee, B.L. (2010) Human serum mannose-binding lectin senses wall teichoic acid Glycopolymer of Staphylococcus aureus, which is restricted in infancy. The Journal of Biological Chemistry, 285, 27167-27175. doi:10.1074/jbc.M110.141309

[54] Neth, O., Jack, D.L., Johnson, M., Klein, N.J. and Turner, M.W. (2002) Enhancement of complement activation and opsonophagocytosis by complexes of mannose-binding lectin with mannose-binding lectin-associated serine protease after binding to Staphylococcus aureus. The Journal of Immunology, 169, 4430-4436.

[55] Topping, D.L. and Mayes, P.A. (1971) The concentration of fructose, glucose and lactate in the splanchnic blood vessels of rats absorbing fructose. Nutrition \& Metabolism, 13, 331-338.

[56] Kawasaki, T., Akanuma, H. and Yamanouchi, T. (2002) Increased fructose concentrations in blood and urine in patients with diabetes. Diabetes Care, 25, 353-357. doi:10.2337/diacare.25.2.353

[57] Muta, T. and Iwanaga, S. (1996) Clotting and immune defense in Limulidae. Progress in Molecular \& Subcellular Biology, 15, 154-189.

[58] Muller, S., Schaffer, T., Flogerzi, B., Seibold-Schmid, B., Schnider, J., Takahashi, K., Darfeuille-Michaud, A., Vazeille, E., Schoepfer, A.M. and Seibold, F. (2010) Mannan-binding lectin deficiency results in unusual antibody production and excessive experimental colitis in response to mannose-expressing mild gut pathogens. Gut, 59, 1493-1500. doi:10.1136/gut.2010.208348

[59] Zuo, D.M., Zhang, L.Y., Lu, X., Liu, Y. and Chen, Z.L. (2009) Protective role of mouse MBL-C on intestinal mucosa during Shigella flexneri invasion. International Immunology, 21, 1125-1134.

[60] Sonnenburg, E.D., Zheng, H., Joglekar, P., Higginbottom, S.K., Firbank, S.J., Bolam, D.N. and Sonnenburg, J.L. (2010) Specificity of polysaccharide use in intestinal bacteroides species determines diet-induced microbiota alterations. Cell, 141, 1241-1252. doi:10.1016/i.cell.2010.05.005 